\title{
RESEARCH
}

\section{Cloning of 559 Potential Exons of Genes of Human Chromosome 21 by Exon Trapping}

\section{Haiming Chen, ${ }^{1}$ Roman Chrast, ${ }^{1}$ Colette Rossier, ${ }^{2}$ Michael A. Morris, ${ }^{2}$ Maria D. Lalioti, ${ }^{1}$ and Stylianos E. Antonarakis ${ }^{1-3}$}

\author{
'Laboratory of Human Molecular Genetics, Department of Genetics and Microbiology, Geneva \\ University Medical School, and ${ }^{2}$ Division of Medical Genetics, Cantonal Hospital of Geneva, Switzerland
}

Chromosome 21 represents $-1 \%$ of the human genome, and its long arm has been estimated to contain 600-1000 genes. A dense linkage map and almost complete physical maps based on yeast artificial chromosomes (YACs) and cosmids have been developed. We have used exon trapping to identify portions of genes from randomly picked chromosome 21-specific cosmids, to contribute to the creation of the transcription (genic) map of this chromosome and the cloning of its genes. A total of 559 different sequences were identified after elemination of false-positive clones and repetitive elements. Among these, exons for 13 of the 30 known chromosome 21 genes have been "trapped." In addition, a considerable number of trapped sequences showed homologies to genes from other species and to human expressed sequence tags (ESTs). One hundred thirty-three trapped sequences were mapped, and every one mapped back to chromosome 21. We estimate that we have identified portions of up to $-40 \%$ of all genes on chromosome 21 . The genic map of chromosome 21 provides a valuable tool for the elucidation of function of the genes and will enhance our understanding of the pathophysiology of Down syndrome and other disorders of chromosome 21 genes.

The cloning of human genes and elucidation of the function of their protein products is of fundamental importance for the understanding of the etiology and pathophysiology of human hereditary disorders. One of the goals of the international effort known as the Human Genome Project is to identify, map, and determine the nucleotide sequences of all human genes (Collins and Galas 1993). The priority of determining the nucleotide composition of protein-coding portions of the genome is justified by the medical relevance of this information with regard to both monogenic disorders and the common disease phenotypes including neoplasias.

Chromosome 21 is the smallest human chromosome, the long arm of which has been estimated to comprise $-1 \%$ of the human genome (Antonarakis 1993). The total number of genes on this chromosome is predicted to be $\sim 600$ 1000 (for the estimation of the total number of human genes, see Fields et al. 1994). The linkage map of chromosome 21 is one of the most dense of all human chromosomes, with more than 120

${ }^{3}$ Corresponding author.

E-MAIL sea@medsun.unige.ch; FAX 41-22-702-5706. highly polymorphic short sequence repeats mapped in a total sex-averaged length of $67 \mathrm{M}$ (McInnis et al. 1993; Antonarakis et al. 1995; A. Chakravarti and S.E. Antonarakis, in prep.). The physical contig of the $38 \mathrm{Mb}$ of the long arm of chromosome 21, using yeast artificial chromosomes (YACs) and other cloning systems [cosmids, P1s, P1 artificial chromosomes (PACs), bacterial artificial chromosomes (BACs)], is almost complete (Chumakov et al. 1992; Nizetic et al. 1994). Only 30 known chromosome 21 genes have been cloned and sequenced to date (Genome DataBase search on June 28, 1995). We have used exon trapping (Buckler et al. 1991; Church et al. 1994) to identify portions of genes and to contribute to the development of the complete transcription (genic) map of this chromosome and thereby to the understanding of the etiology of the phenotypes of Down syndrome and other disorders involving chromosome 21 genes. We report here the cloning, sequencing, and partial characterization of DNA sequences that represent portions of up to $\sim 40 \%$ of the predicted number of genes on human chromosome 21. Further study of the cDNAs corresponding to the trapped exons will enhance our understanding of chromosome 21-related disorders and the 


\section{CHEN ET AL.}

role of this chromosome in normal human development and physiology.

\section{RESULTS}

The method of exon trapping (Buckler et al. 1991; Church et al. 1994) was used to identify portions of human genes that map on chromosome 21. Cosmids taken at random from the chromosome 21-specific library LL21NCO2-Q (Soeda et al. 1995) were used for identification of genes throughout the entire chromosome. A total of 1194 cosmids were used. Pools of 10 cosmids were used for each trapping experiment. In only a few experiments, all cosmids from a 96microliter well plate were used. Clones that contained human ribosomal RNA (RNR) sequences and mouse genomic sequences were eliminated and not used for trapping (see Methods). Because the average length of the inserts was $\sim 40 \mathrm{~kb}$, the 1194 cosmids represent $\sim 48 \mathrm{Mb}$ of chromosome 21 DNA, which is similar to the estimated size of both arms of this chromosome (Ichikawa et al. 1993). After elimination of false-positive exons caused by vector self-splicing events (see Methods), a total of 1030 potential exons were trapped and sequenced (Table 1). Of these, 619 were unique sequences, whereas the remaining 411 were redundant. Fifty-five different trapped sequences showed homology to highly or moderately repeated humam genomic elements (including Alu, LINE, MER1 repeats, and RNR genes; see Table 1); five clones contained contaminant Escherichia coli sequences. After elimination of these 60 sequences, a total of 559 different trapped sequences were identified. The complete nucleotide sequences of all of these potential exons have been deposited in EMBL/GenBank (accession nos. X88001-X88560, X86349-X86351, X83219, X84366, and X83513-X86516).

The size distribution of the different trapped sequences is shown in Figure 1. The mean size of the trapped exons was 125 nucleotides with a standard deviation of 60 nucleotides; the median size was 115 nucleotides. The GC content of the trapped sequences is similar to that of cDNAs and distinctly higher than that of genomic sequences. The GC content of $1114 \mathrm{~kb}$ of genomic sequences was $42.5 \%$, whereas that of $259 \mathrm{~kb}$ of cDNAs was $49.6 \%$ (sequences were selected randomly from the GenBank/EMBL data bases). The GC content of the trapped sequences reported here (total sequence length of $65.4 \mathrm{~kb}$ ) was $51.4 \%$.
A total of 30 exons (5.4\% of the 559 different sequences) were identical to exons of 13 genes identified previously, known to map on human chromosome 21 . These homologies are shown in Table 2.

Table 3 shows the findings of the remaining homology searches. We used the probability of $10^{-4}$ as a cutoff point for significance in the homology searches. Using this criterion, a total of $378(67.6 \%$ of 559$)$ of potential exons did not show significant homologies to existing entries in the nucleotide and protein data bases. Fiftythree sequences $(9.5 \%$ of 559 ) showed identity or strong homology to human expressed sequence tags (ESTs) (Table 3F). The predicted translation products of 83 trapped sequences ( $14.8 \%$ of 559 ) showed a considerable degree of homology to proteins from the data bases. The homology was convincing in 49 (Table $3 \mathrm{~A}$ ), but weaker in 21 , of those exons (Table 3D); 9 had homologies to the collagen gene families (Table 3B), and 7 to Pro- or Cys-rich proteins (Table $3 \mathrm{C}$ ). Some of the outstanding homologies include those to predicted polypeptides of genes for Drosophila singleminded, white, and enhancer of zeste, rat lanosterol synthase, and megalin, bovine ATP synthase OSCP subunit, yeast PWP2 and one protein kinase, Xenopus neural cell-adhesion molecule, mouse pericintrim, T-cell invasion and metastasis protein, requiem, human coagulation factor 11 , and elastase $2 b$ (see corresponding GenBank accession nos. for their references). Three further sequences were identical to cloned but unmapped human genes such as the GABPA transcription factor (Watanabe et al. 1993) and members of the $\beta 2$-chimerin gene family (Leung et al. 1994) (Table $3 A$, sequences 1-3). Some clones (Table 3F, e.g., sequences 133-139) showed identity to areas of chromosome 21 that have been sequenced as part of the cosmid sequencing project at the Lawrence Berkeley laboratory (C.H. Martin, M.M. Bondoc, A. Chiang, T. Cloutier, C.A. Davis, C.L. Ericsson, M.A. Jaklevic, R.J. Kim, M.T. Lee, M. Li, C.A. Mayeda, A. Steiert-El Kheir, and M.J. Palazzolo, unpubl.; GenBank accession no. L35676).

A subset of the trapped exons have been mapped back to chromosome 21 using different methods. To date, not a single trapped exon tested has been mapped in a genomic region outside of human chromosome 21. A total of 133 exons have been mapped to chromosome 21 by (1) hybridization or PCR amplification using chromosome 21 cosmids (67 exons), YACs (35 
EXON IRAPPING ON HUMAN CHROMOSOME 21

Table 1. Results of the Exon Trapping Experiment Using Randomly Picked
Chromosome 21-specific Cosmids.

\begin{tabular}{|c|c|c|}
\hline & Number (\%) & Duplicates \\
\hline Total clones sequenced ${ }^{\mathrm{a}}$ & 1030 & \\
\hline Different trapped sequences ${ }^{a}$ & 619 & $(+411)$ \\
\hline Different trapped sequences ${ }^{b}$ & 559 & $(+391)$ \\
\hline \multicolumn{3}{|l|}{ Known genes on HC21 (Table 2) } \\
\hline known HC21 genes hit & 13 & \\
\hline different trapped sequences & $30(5.4 \%$ of 559$)$ & $(+43)$ \\
\hline Excellent homologies (Table 3 ) up to $P<10^{-4}$ & $83(14.8 \%$ of 559$)$ & $(+71)$ \\
\hline convincing homologies to genes & $49(8.7 \%$ of 559 & $(+43)$ \\
\hline weaker homologies to genes & $21(3.7 \%$ of 559$)$ & $(+21)$ \\
\hline collagen gene family homologies ${ }^{c}$ & $9(1.6 \%$ of 559$)$ & $(+1)$ \\
\hline pro- or cys-rich protein homologies & $7(1.2 \%$ of 559$)$ & $(+6)$ \\
\hline Known but unmapped human genes & $3(0.5 \%$ of 559$)$ & $(+3)$ \\
\hline ESTs & $53(9.5 \%$ of 559$)$ & $(+45)$ \\
\hline "Minus" strand homologies & $5(0.9 \%$ of 559$)$ & $(+1)$ \\
\hline New trapped sequences & $526(94.1 \%$ of 559$)$ & $(+46)$ \\
\hline Repetitive elements & $55(8.9 \%$ of 619$)$ & $(+20)$ \\
\hline RNR genes & 4 & \\
\hline Alu element & 33 & \\
\hline LINE & 3 & \\
\hline MER repeat & 4 & \\
\hline Mstll repeat & 2 & \\
\hline pericentric 48 bp repeat & 1 & \\
\hline THE-1 element & 1 & \\
\hline O family repeat & 1 & \\
\hline$\alpha$ satellite & 1 & \\
\hline TR7 repeat & 2 & \\
\hline SST repeat & 1 & \\
\hline THR repeat & 1 & \\
\hline Contaminants ( $E$. coli sequences) & 5 & \\
\hline Total trapped sequences mapped to $\mathrm{HC} 21$ & 133 of $133(23.8 \%$ of 559$)$ & \\
\hline
\end{tabular}

exons), and rodent-human somatic cell hybrids (40 exons); (2) because they were identical to chromosome 21 genes identified previously (30 exons); (3) because they were identical to sequences from chromosome 21 (39 exons). A few exons were additionally mapped by fluorescence in situ hybridization (FISH) analysis using their corresponding cosmids as probes. Some exons were mapped to chromosome 21 by more than one means (Table 3 ).

To verify whether the trapped sequences contain parts of genes, we performed cDNA library screening using pools of these sequences as probes. Two pools of 50 trapped sequences were hybridized to 300,000 plaques of two cDNA libraries: Pool 1 was hybridized to an amplified retina cDNA library (Nathans et al. 1986), and pool 2 to a commercially available fetal brain cDNA library (Clontech). A total of 126 and 29 strongly positive plaques were identified, respectively, after overnight autoradiography. Two complex probes from 20 and 23 plaque-purified clones were made by PCR amplification from pooled DNA from these clones, and hybridized against the original 100 trapped sequences. A total of 5 and 12 trapped sequences were positive 


\section{CHEN ET AL.}

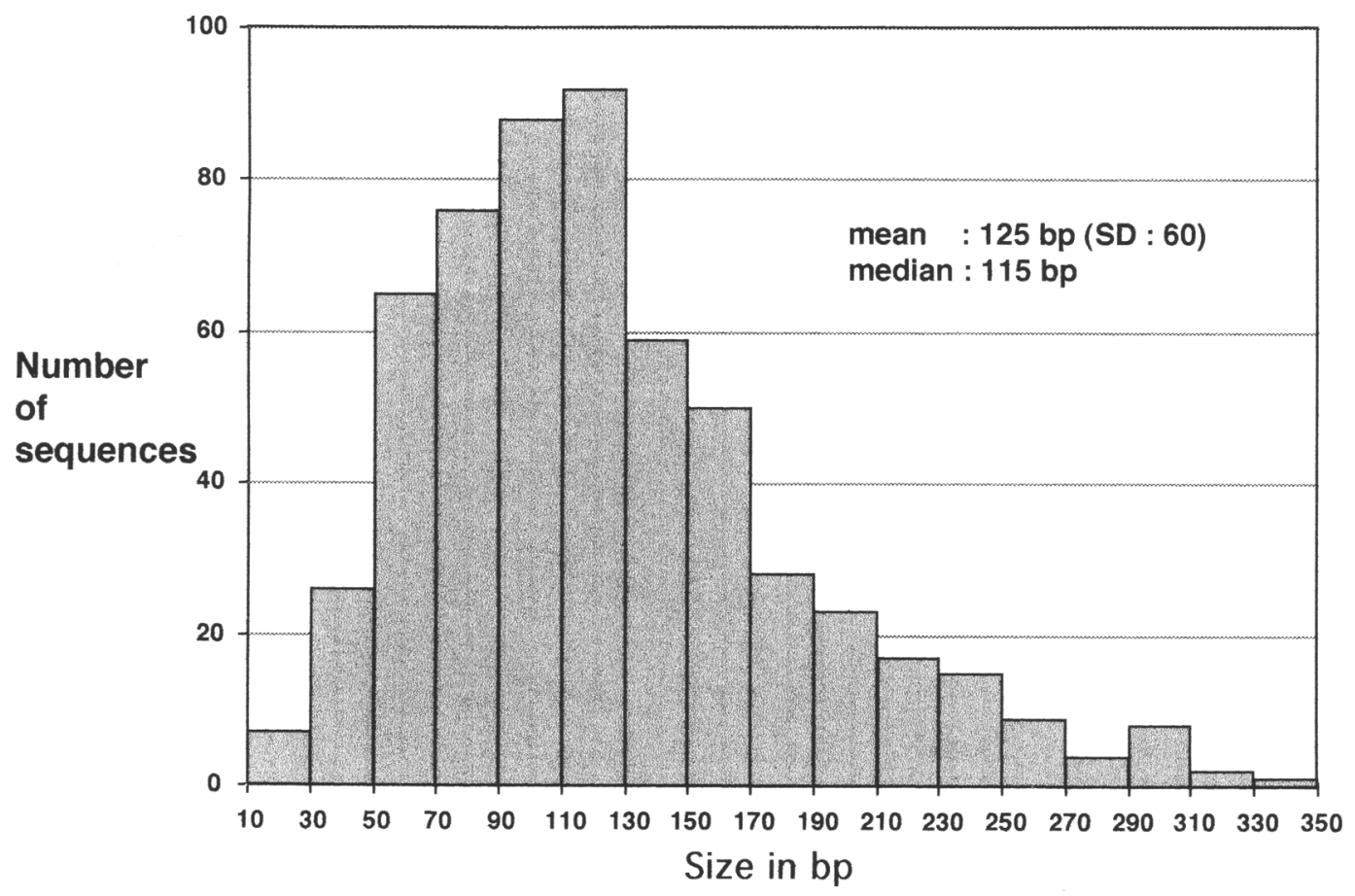

Figure 1 Histogram of sizes (in nucleotides) of the 559 different exon-trapped sequences.

from pools 1 and 2, respectively. As 20 of 126 and 23 of 29 strongly positive plaques were used to generate the probes for back-hybridization, these data imply that at least 31 and 15 trapped sequences from pools 1 and 2 , respectively, are present in these cDNA libraries $(62 \%$ and $30 \%$ of trapped clones). It should be noted that these are underestimates because (1) pooled probes were used (selecting against small or poorly labeled exons); (2) only strongly positive cDNA clones were picked; (3) the back-hybridization probes were generated by whole-insert PCR (selecting against large inserts); and (4) cDNA libraries from only two tissues were tested.

\section{DISCUSSION}

We have used exon trapping to clone gene fragments and contribute to the transcription (genic) map of chromosome 21 . This method was chosen because it is independent of the tissue-specific, temporal, and spatial expression of genes and does not rely on the abundance of a particular clone in a given cDNA library (Buckler et al. 1991; Brennan and Hochgeschwander 1995). Targeted experiments with a cosmid containing the entire PFKL gene (the sequence of its exons and splice juctions were known) (Elson et al. 1990) showed that the method captures genomic portions demarkated by donor and acceptor splice sites; although cryptic splice sites can be used in the experimental strategy, the majority of the trapped sequences contained at least one authentic splice site of exons (data not shown).

Pools of randomly picked chromosome 21 cosmids were used to trap the exons. We estimate that we have identified portions of $\leqslant 40 \%$ of chromosome 21 genes for two reasons: (1) As expected, a number of exons from the chromosome 21 genes cloned previously were also identified by our whole-chromosome approach. Exons from a total of 13 genes identified previously have been sequenced (Table 2). Because nucleotide sequences of 30 chromosome 21 genes with more than two exons are included in the sequence data bases, we conclude that we have probably captured $-40 \%$ of the genes of this chromosome. (2) For these 13 known chromosome 21 genes, a total of 30 different exons have been captured (one known exon for every 19 trapped different sequences) of 2.3 exons per known gene. If the same numbers apply to the remainder of the trapped exons, the 526 additional different captured sequences correspond to -230 genes. If the total number of genes on the long arm of human chromosome 21 (which is 


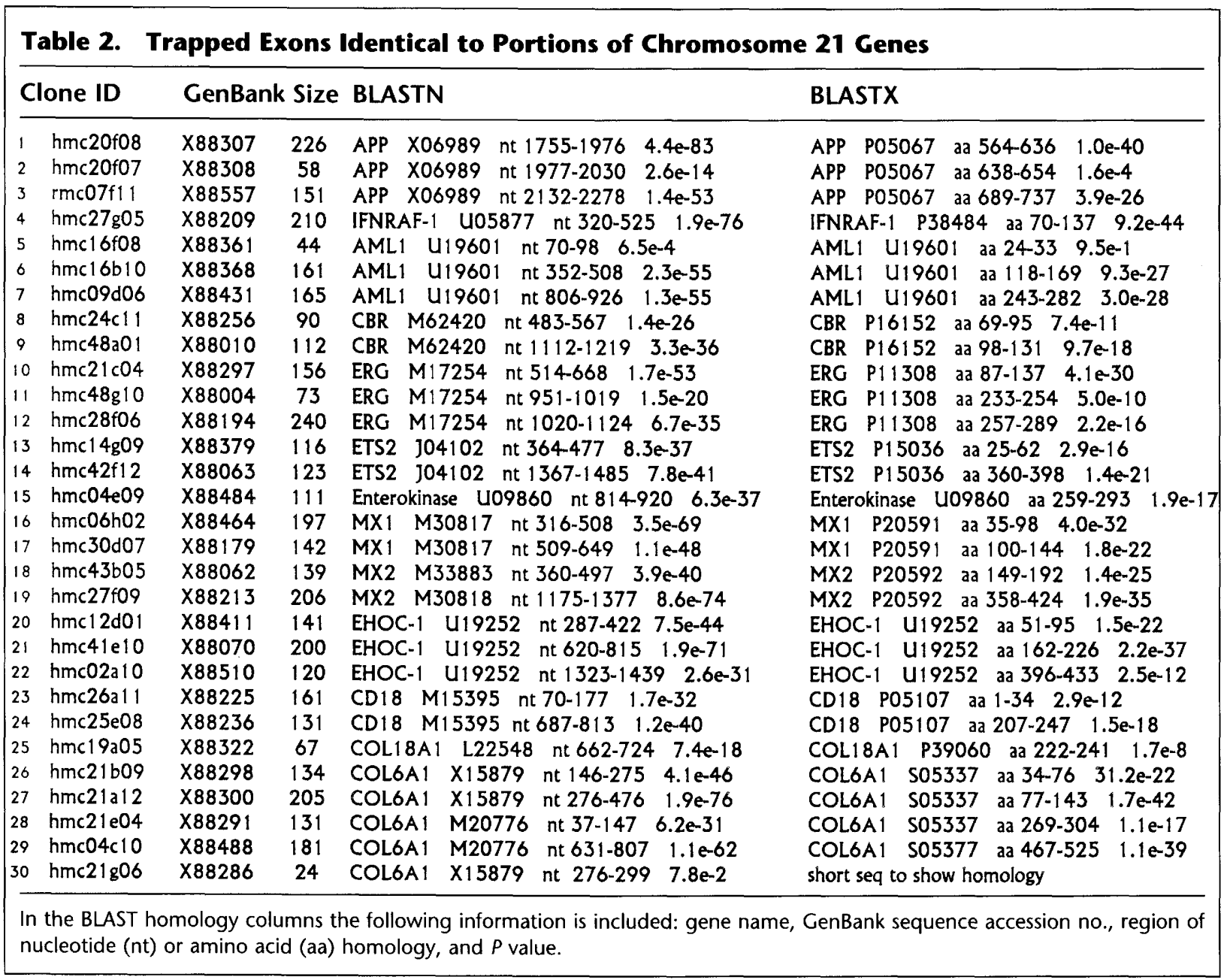

$\sim 1 \%$ of the human genome) is between $600-$ 1000 , then we estimate that the unknown exons described here represent portions of $23 \%-38 \%$ of the genes on chromosome 21 .

A total of 1194 cosmids were used in the experiments described here and 559 different exons have been identified, representing an average of 0.47 exons per cosmid used, or one exon per 85 $\mathrm{kb}$ of DNA. These numbers are not different from the experience of other investigators who have used exon trapping with similar numbers of cosmids for each pool (Buckler et al. 1991; Church et al. 1993). The continuation of the exon trapping experiment with $\sim 1500$ more cosmids will result in the cloning of exons from perhaps as much as $80 \%-90 \%$ of the genes on chromosome 21 . It is difficult, however, to achieve a more complete coverage of the transcription (genic) map before a cosmid contig has been determined, and all the captured exons have been mapped back to their corresponding cosmid clones. Cosmids from this contig with no corresponding exons, or cosmids not used previously for exon trapping could then be used for directed completion of the transcription map. Futhermore, because exon trapping does not identify gene portions from genes with less than three exons (exons without both donor and acceptor splice sites), other methods should be used for the identification of such genes. For example, the genes for $\mathrm{Na}^{+} /$myo-inositol cotransporter (Berry et al. 1995) and Isk potassium channel (Murai et al. 1989) are intronless, and therefore they could not have been identified by the strategy described here. Other methods, such as 3' exon trapping (Krizman and Berget 1993), or cDNA selection (Parimoo et al. 1991; Lovett et al. 1991), among others will therefore be required for the completion of the transcription map. Three studies using cDNA selection that identified a number of cDNAs from certain regions of 


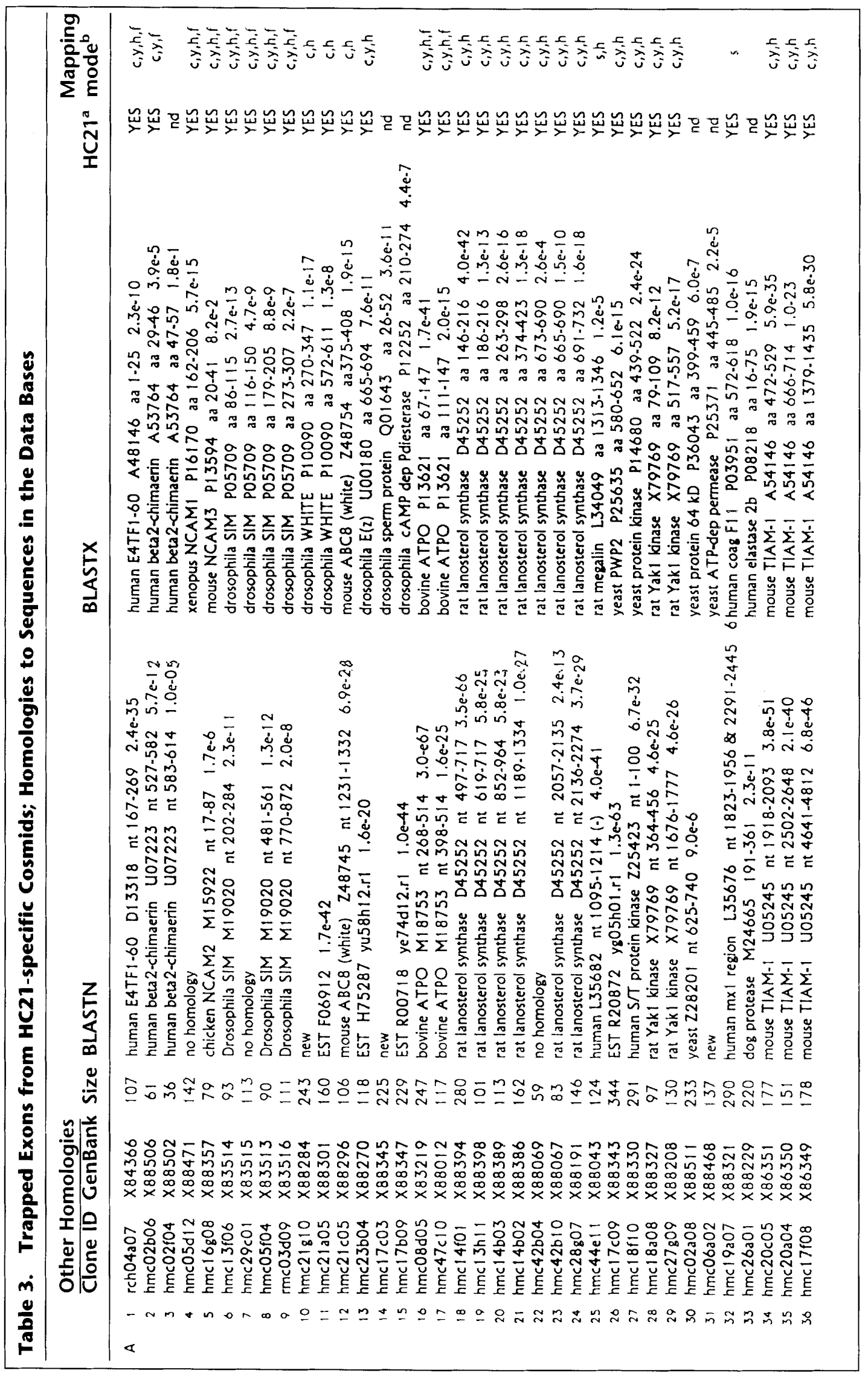




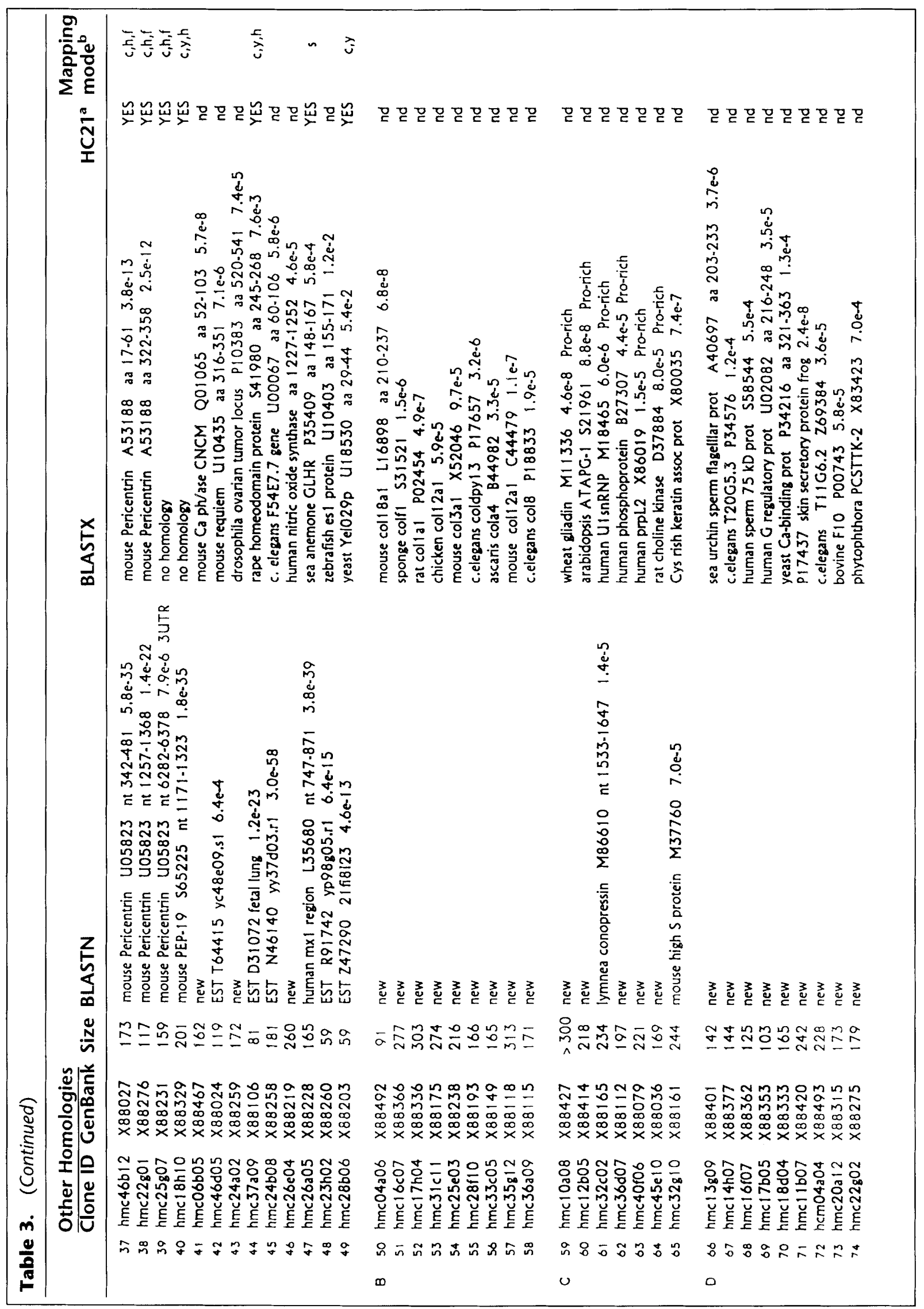


CHEN ET AL.

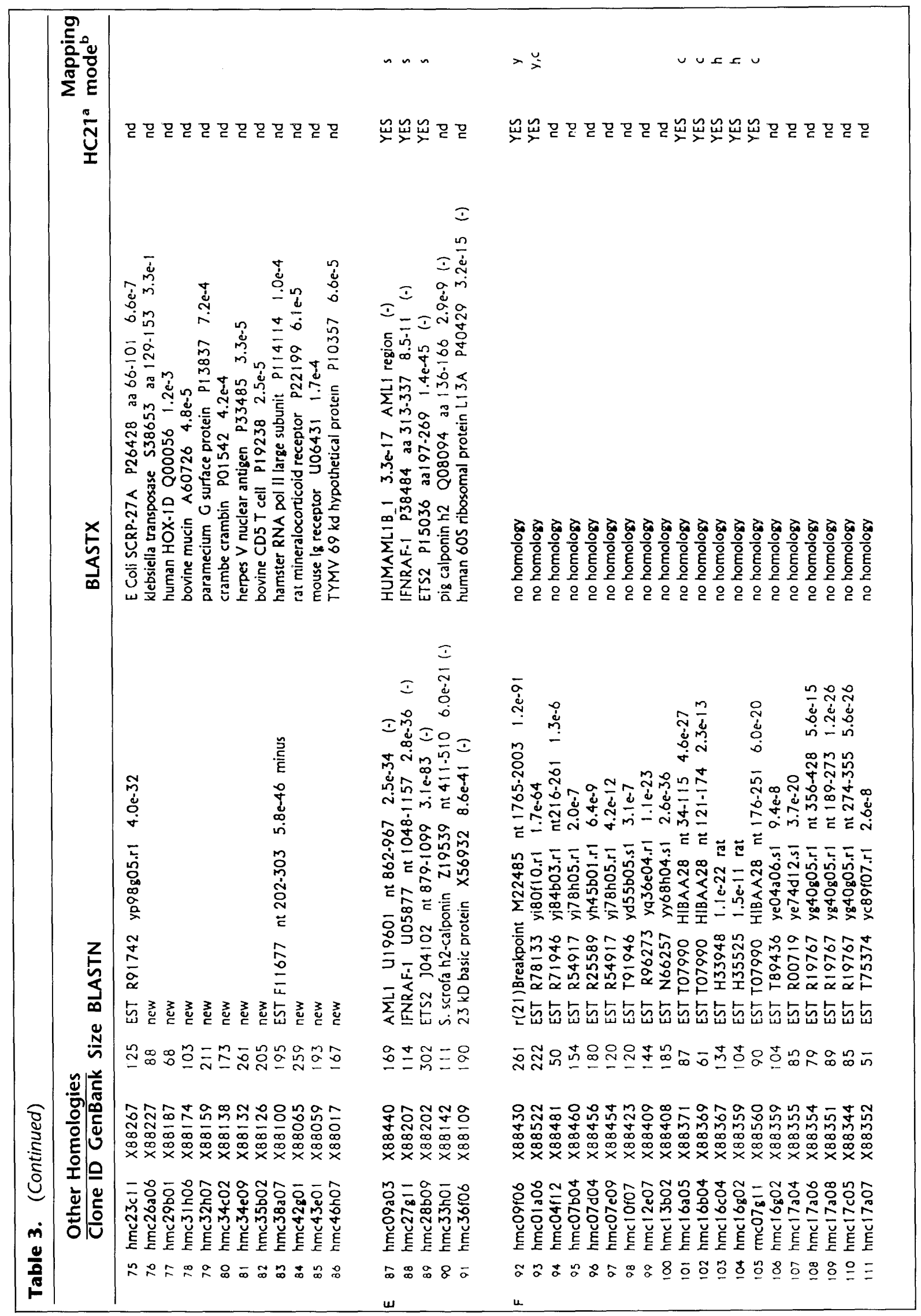


EXON IRAPPING ON HUMAN CHROMOSOME 21

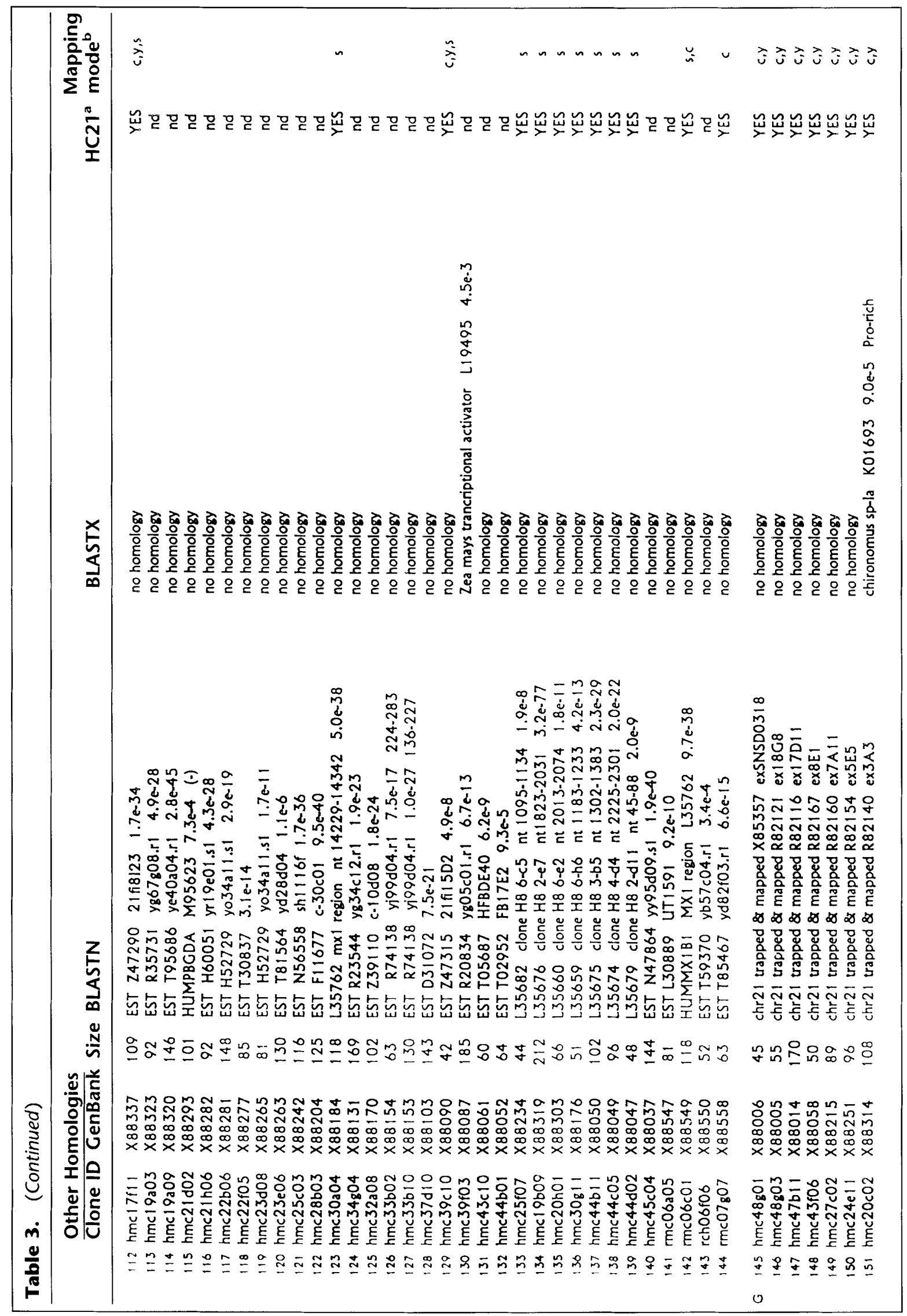


CHEN ET AL.

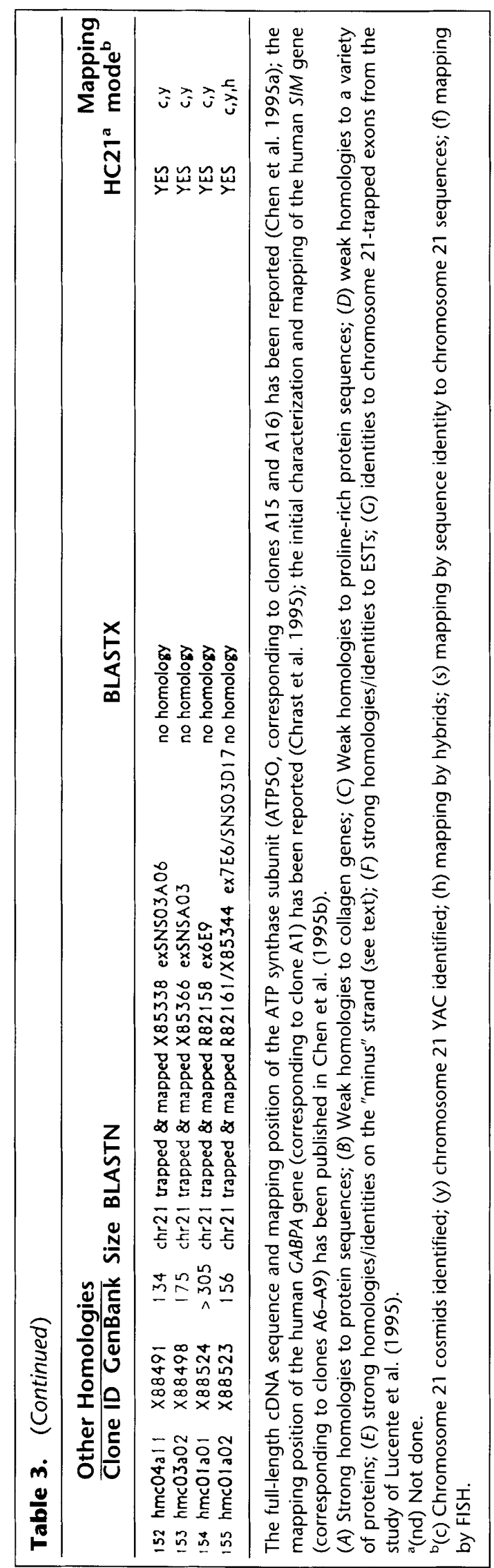




\section{EXON IRAPPING ON HUMAN CHROMOSOME 21}

chromosome 21 have been published recently (Cheng et al. 1994; Peterson et al. 1994; Xu et al. 1995).

The predicted encoded polypeptides of a total of 49 exons $(8.7 \%)$ had high homologies to proteins from other species or to related human proteins (Table $3 \mathrm{~A}$ ). This subset of sequences is among the most interesting in the short term because some (albeit hypothetical) predictions can be made about functions, leading potentially to the identification of genes that are candidates for specific phenotypes. These exons include, among others, homologies to the following genes: Drosophila single-minded, white locus, and enhancer of zeste, rat lanosterol synthase, and megalin, bovine ATP synthase OSCP subunit, yeast PWP2 and protein kinase, Xenopus neural cell-adhesion molecule, mouse pericentrin, T-cell invasion and metastasis, and requiem, humam coagulation factor 11 and elastase $2 b$.

There are several lines of evidence to suggest that the majority of the trapped sequences are fragments of genes: (1) Sequence homology searches identity to many ESTs from various cDNA libraries (Table 3F); (2) a considerable number of homologies to genes from other species have been identified (for some of these, the corresponding full-length cDNA of the human homolog has been cloned; e.g., see Chen et al. 1995a); (3) the GC content of the trapped sequences is more similar to cDNAs than to genomic DNA (for the differences in GC content in the completely sequenced chromosome XI of Saccharomyces cerevisiae, see Dujon et al. 1994; for the GC content of the human genome, see Saccone et al. 1993); (4) a number of exons for known chromosome 21 genes have been obtained; and (5) the use of pools of trapped sequences as probes against cDNA libraries identified a substantial number of positive cDNA clones.

The sequencing of the trapped inserts from pAMP10 using oligonucleotide SD2 (see Methods) is directional, that is, from the acceptor toward the donor splice site used, and therefore the homology with known transcripts should always be with the coding strand. In a few instances, however, we have identified significant homologies with the "minus" strand (Table 3E). For example, homologies with $P<10^{-33}$ were found with regions of the chromosome 21 genes $A M L 1$, IFNAR-1, and ETS2, suggesting that there are either transcripts from overlapping genes in opposite directions of that acceptor and donor-like splice sites have been used from the noncoding strand. These possibilities will be tested by isolating and studying any existing corresponding cDNAs.

Exon trapping was applied recently to a 2.5 $\mathrm{Mb}$ region of chromosome 21 that has been associated with some features of Down syndrome (Lucente et al. 1995). A total of 102 trapped sequences have been reported and mapped to cosmid clones of the region; the average exon density was 1 in every $25 \mathrm{~kb}$. A total of 13 exons from the present study were identical to those reported in Lucente et al. (1995) (Table 3G; exons for SIM and $E R G$ genes). Furthermore, both exon trapping and cDNA selection have been applied to 81 cosmids of plate 5 of the chromosome 21-specific LL21NC02-Q cosmid library (Yaspo et al. 1995). After elimination of repetitive elements, a total of 21 apparently different transcription units were identified. Because we did not use plate 5 in our experiments, the cosmids used in the present study and that of Yaspo et al. (1995) were different. Data base searches revealed that our trapped sequences identified portions of four of these transcription units (TU4, 5, 8, 13; Yaspo et al. 1995).

It appears that there are gene-rich and genepoor regions on 21q. To investigate the gene density, Tassone et al. (1995) used cDNA selection from six cDNA libraries to 16 YACs mapped throughout 21q. They found that the regions $21 \mathrm{q} 22.3$ and $21 \mathrm{q} 22.1$ are gene-rich as compared with regions $21 \mathrm{q} 11.2,21 \mathrm{q} 21$, and $21 \mathrm{q} 22.2$, which yielded very few genes (Yaspo et al. 1995). These results are in agreement with the gene-rich isochores (Saccone et al. 1993), and the distribution of NotI restriction sites (Ichikawa et al. 1993) and of CpG islands (Tassone et al. 1992). Our mapping experiments of selected exons, although nonsystematic and complete is in agreement with the results of Tassone et al. (1992); slighty more than half $(54 \%)$ of the mapped exons localize to the most distal band 21q22.3.

The precise mapping of all the trapped sequences reported here on chromosome 21 and the study of their corresponding cDNAs will enhance our understanding of the gene distribution on $21 \mathrm{q}$ and the contribution of this chromosome to human pathologies. In particular, candidate genes involved in Down syndrome and monogenic disorders that map on chromosome 21 can be studied using the clones and nucleotide sequences reported here. We have demonstrated additionally that the exon trapping methodology 
using DNA material from a single chromosome can be used to isolate portions of the majority of the genes of this chromosome and the completion of the transcription maps. Matching of sequences from these monochromosomal exon trapping experiments with those of the fast progressing EST sequencing programs will immediately provide mapping information on a large number of ESTs and their corresponding clones.

\section{METHODS}

\section{Exon Trapping}

Genomic DNA cloned in the Lawrence Livermore LL21NCO2-Q chromosome 21-specific cosmid library was used for the exon trapping protocol (instruction manual 18449-017, 1994, GIBCO-BRL). This library, constructed in Lawrist 16 vector, was kindly provided by P. deJong (Soeda et al. 1995). DNA from the 10,368 clones arrayed in 108 microliter plates was spotted onto Hybond membranes ( 1536 clones per $8 \times 12 \mathrm{~cm}^{2}$ filter). Hybridization of these filters with total mouse DNA or $18 \mathrm{~S}$ and $28 \mathrm{~S}$ RNR (probes $\gamma-5.8$ and $\gamma-7.3$ kindly provided by S. Parimoo, Yale University, New Haven, CT) permitted the recognition of clones with either mouse DNA inserts (1135 clones of $10.9 \%$ of the total) or RNR repeats (501 clones or $4.8 \%$ of total). The identities of these clones are available on request to haiming@medsun.unige.ch. Pools of 10 cosmid clones from plates Q49 to Q61 and Q63 to Q65 were digested with Pstl, and the fragments were subcloned in plasmid pSPL3 (Church et al. 1994). In some experiments, pools of cosmids from entire microliter plates (Q57, Q58, Q60, Q63, Q64, Q21, Q31, Q35, and Q36) were used after digestion with EcoRI. Cosmids containing mouse DNA and RNR sequences were excluded from the above experiments. Recombinant plasmids were transfected into $\cos 7$ cells using lipofectACE (exon trapping protocol, GIBCO$\mathrm{BRL}$ ). After $24 \mathrm{hr}$, total RNA from cos7 cells was reversetranscribed and PCR-amplified using primers complementary to pSPL3 sequences (exon trapping protocol, GIBCO$\mathrm{BRL}$ ). The reverse transcriptase PCR (RT-PCR) products were subcloned into vector pAMP10 using uracil DNA glycosylase (UDG) cloning (exon trapping protocol, GIBCOBRL). To eliminate clones that contained false-positive exons attributable to pSPL3 self-splicing (which range from $8 \%-35 \%$ of clones in different experiments), the cloned PCR products were hybridized with oligonucleotides $5^{\prime}$ TAGCAATAGTAGCATTAGTA-3', 5'-TGCTAAAGCATATGATACAG-3', 5'-TCATTCTTCAAATCAGTGCA-3', and 5'GGATATTCACCATTATCGTT-3' (which extended from pSPL3 nucleotides 731-750, 1111-1130, 1331-1350, and 3071-3090, respectively) and the positive subclones were eliminated from further analysis.

\section{Nucleotide Sequencing and Data Base Comparisons}

The trapped sequences were subjected to nucleotide sequencing with $T a q$ polymerase by the dye terminator method using oligonucleotide SD2 5'-GTGAACTGCACT-
GTGACAAGCTGC- $3^{\prime}$ (which is complementary to the $5^{\prime}$ exon provided by the pSPL3 vector) on an AB1373 sequencer. The nucleotide sequences and their predicted translation products in all six reading frames were then used for sequence comparisons against all available nucleotide and protein data bases; the homology search algorithms used were BLASTN and BLASTX (Alschul et al. 1990), and in some cases FASTDB (Brutlag et al. 1990). Data base matches with significance $<10^{-4}$ were considered nonsignificant (unless the test sequence was $<50$ nucleotides) and the sequences were considered novel. All sequences reported in this papaer have been deposited in the EMBL/GenBank data bases (accession nos. X88001X88560, X886349-X86351, X83219, X84366, and X83513-X86516).

\section{Genomic Mapping of Trapped Sequences}

A subset of the trapped sequences were mapped to chromosome 21 by several methods, including PCR amplification from DNA of YACs, cosmids, or somatic cell hybrids, Southern hybridization, and FISH. Radioactive hybridization probes were prepared from the inserts of selected recombinant pAMP10 plasmids by PCR amplification using oligonucleotides dUSD2 and dUDA4 (exon trapping protocol, GIBCO-BRL). These probes were used for filter hybridization against the chromosome 21 cosmid library LL21NC02-Q the collection of the YACs from the chromosome 21 YAC contig (Chumakov et al. 1992), and restriction endonuclease-digested genomic DNA from rodent-human somatic cell hybrids containing defined fragments of human chromosome 21 (kindly donated by D. Patterson) (Patterson et al. 1993), from human genomic DNA, and from genomic DNA from yeast clones containing specific YACs. PCR amplification using oligonucleotide primers corresponding to selected trapped sequences was used on template DNA from chromosome 21-specific cosmids, YACs, somatic cell hybrids, and human, mouse, and Chinese hamster DNAs. FISH (Lichter et al. 1988) was performed in a few cases using cosmids positive for certain trapped sequences.

\section{Identification of Corresponding cDNAs}

Pools of either 50 or 30 trapped sequences were each used as probes against $\sim 300,000$ plaques from humna retina (Nathans et al. 1986) or fetal brain cDNA libraries (Clontech). A proportion of the positive clones were plaquepurified and used as hybridization probes against filters containing the trapped exons.

A number of trapped sequences were used as hybridization probes against cDNA libraries after PCR amplification of the insert. The cDNA library of choice was the normalized infant brain library (Soares et al. 1994). Single clones or pools of five trapped sequences were used for hybridization against the 40,000 clones of this library arrayed in 11 filters (3456 clones per filter). Other cDNA libraries used during the experiments include adult brain, heart, kidney, testis, colon, and 11-week-old human embryo (Clontech; gifts from P. Goodfellow, Cambridge University, UK; D. Kurnit, University of Michigan, Ann Arbor; D. Karagogeos, University of Crete, Herkalion, Greece). 


\section{EXON TRAPPING ON HUMAN CHROMOSOME 21}

\section{ACKNOWLEDGMENTS}

This study was supported by grants from the Swiss Fonds National de Recherche Scientifique 31.33965.92, 31.40500.94, and European Union grant GENE-CT930015, and the Geneva University and Hospital funds to S.E.A. We thank Pieter deJong for the chromosome 21specific cosmid library LL21NC02-Q, David Patterson for the chromosome 21-specific somatic cell hybrids, and Laurent Roux for the cos7 cell line. We also thank Isabelle Moix, Michele Young-Bellido, Sonia Samec, Arnaud Gos, and Jianying $\mathrm{Su}$ for their contributions in some experiments and Amos Bairoch for help in data base searches. The sequence data described in this paper have been submitted to the EMBL/GenBank data library under accession numbers X88001-X88560, X86349-X86351, X83219, X84366, and X83513-X86516.

The publication costs of this article were defrayed in part by payment of page charges. This article must therefore be hereby marked "advertisement" in accordance with 18 USC section 1734 solely to indicate this fact.

\section{REFERENCES}

Altschul, S.F., W. Gish, W. Miller, E.W. Myers, and D.J. Lipman. 1990. Basic local alignment search tool. J. Mol. Biol. 215: 403-410.

Antonarakis, S.E. 1993. Human chromosome 21: Genome mapping and exploration, circa 1993. Trends Genet. 9: 142-148.

Antonarakis, S.E., D. Patterson, C. Van Broeckhoven, N. Shimizu, K. Gardiner, J. Delabar, J. Korenberg, and R. Reeves. 1995. Report of the committee on the genetic constitiution of chromosome 21. In Human gene mapping 1994 (ed. A.J. Cuttichia), pp. 732-766. Johns Hopkins University Press, Baltimore, MD.

Berry, G.T., J.J. Mallee, H.M. Kwon, J.S. Rim, W.R. Mulla, M. Muenke, and N.B. Spinner. 1995. The human osmoregulatory $\mathrm{Na}^{+} /$myo-inositol cotransporter gene (SLC5A3): Molecular cloning and localization to chromosome 21. Genomics 25: 507-513.

Brennan, M.B. and U. Hochgeschwander. 1995. So many needles, so much hay. Hum. Mol. Genet. 4: 153-156.

Brutlag, D.L., J.P. Dautricourt, S. Maulik, and J. Relph. 1990. Improved sensitivity of biological sequence database searches. Comp. Appl. Biosci. 6: 237-245.

Buckler, A.J., D.D. Chang, S.L. Graw, J.D. Brook, D.A. Haber, P.A. Sharp, and D.E. Housman. 1991. Exon amplification: A strategy to isolate mammalian genes based on RNA splicing. Proc. Natl. Acad. Sci. 88: 4005-4009.

Chen, H., M.A. Morris, C. Rossier, J.L. Blouin, and S.E. Antonarakis. 1995a. Cloning of the cDNA for the human ATP synthase subunit (ATP5O) by exon trapping and mapping to chromosome 21 Genomics 28: 470-476.

Chen, H.M., R. Chrast, C. Rossier, A. Gos, S.E.
Antonarakis, J. Kudoh, A. Yamaki, N. Shindoh, H. Maeda, S. Minoshima, and N. Shimizu. 1995b. Single-minded and Down syndrome? Nature Genet. 10: $9-10$.

Cheng, J.F., V. Boyartchuk, and Y. Zhu. 1994, Isolation and mapping of human chromosome 21 cDNA: Progress in constructing a chromosome 21 expression map. Genomics 23: 75-84.

Chrast, R., H.M. Chen, M.A. Morris, and S.E. Antonarakis. 1995. Mapping of the human transcription factor GABPA gene to chromosome 21. Genomics 28: $119-122$.

Chumakov, I., P. Rigault, S. Guillou, P. Ougen, A. Billaut, G. Guasconi, P. Gervy, I. LeGall, P. Soularue, L. Grinas, L. Bougueleret, C. Bellanne-Chantelot, B. Lacroix, E. Barillot, P. Gesnouin, S. Pook, G. Vaysseix, G. Frelat, A. Schmitz, J.L. Sambucy, A. Bosch, X. Estivill, J. Weissenbach, A. Vignal, H. Riethman, D. Cox, D. Patterson, K. Gardiner, M. Hattori, Y. Sakaki, H. Ichikawa, M. Ohki, D. Le Paslier, R. Heilig, S.E. Antonarakis, and D. Cohen. 1992. A continuum of overlapping clones spanning the entire chromosome 21q. Nature 359: 380-386.

Church, D.M., L.T. Banks, A.C. Rogers, S.L. Graw, D.E. Housman, J.F. Gusella, and A.J. Buckler. 1993. Identification of human chromosome 9 specific genes using exon amplification. Hum. Mol. Genet. 2: $1915-1920$.

Church, D.M., C.J. Stotler, J.L. Rutter, J.R. Murrell, J.A. Trofatter, and A.J. Buckler. 1994. Isolation of genes from complex sources of mammalian genomic DNA using exon amplification. Nature Genet. 6: 98-105.

Collins, F. and D. Galas. 1993. A new five-year plan for the U.S. human genome project. Science 262: 43-46.

Dujon, B., D. Alexandraki, B. André, W. Ansorge, V. Baladron, J.P. Ballesta, A. Banrevi, P.A. Bolle, M. Bolotin-Fukuhara, P. Bossier, G. Bou, J. Boyer, M.J. Buitrago, G. Chéret, L. Colleaux, B. Daignan-Fornier, F. del Rey, C. Dion, H. Domdey, A. Düsterhöft, S. Düsterhus, K.-D. Entian, H. Erfle, P.F. Esteban, H. Feldmann, L. Fernandes, G.M. Fobo, C. Fritz, H. Fukuhara, C. Gabel, L. Gaillon, J.M. Carcia-Cantalejo, J.J. Garcia-Ramirez, M.E. Gent, M. Ghazvini, A. Goffeau, A. Gonzalez, D. Grothues, P. Guerreiro, J. Hegemann, N. Hewitt, F. Hilger, C.P. Hollenberg, O. Horaitis, K.J. Inge, A. Jacquier, C.M. James, J.C. Jauniaux, A. Jimenez, H. Keuchel, L. Kirchrath, K. Kleine, P. Kötter, P. Legrain, S. Liebl, E.J. Louis, A. Maia e Silva, C. Mark, A.-L. Monnier, D. Möstl, S. Müller, B. Obermaier, S.G. Oliver, C. Pallier, S. Pascolo, F. Pfeiffer, P. Philippsen, R.J. Planta, F.M. Pohl, T.M. Pohl, R. Pöhlmann, D. Portetelle, B. Purnelle, V. Puzos, M. Ramezani Rad, S.W. Rasmussen, M. Remacha, J.L. Revueita, G.-F. Richard, M. Rieger, C. Rodrigues-Pousada, M. Rose, T. Rupp, M.A. Santos, C. Schwager, C. Sensen, J. Skala, H. Soares, F. Sor, J. Stegemann, H. Tettelin, A. Thierry, M. Tzermia, L.A. 


\section{CHEN EI AL.}

Urrestarazu, L. van Dyck, J.C. van Vliet-Reedijk, M. Valens, M. Vandenbol, C. Vilela, S. Vissers, D. von Wettstein, H. Voss, S. Wiemann, G. Xu, J. Zimmermann, M. Haasemann, I. Becker, and H.W. Mewes. 1994. Complete DNA sequence of yeast chromosome XI. Nature 369: 371-378.

Elson, A., D. Levanon, M. Brandeis, N. Dafni, Y. Bernstein, E. Danciger, and Y. Groner. 1990. The structure of the human liver-type phosphofructokinase. Genomics 7: 47-56.

Fields, C., M.D. Adams, O. White, and J.C. Venter. 1994. How many genes in the human genome? Nature Genet. 7: 345-346.

Ichikawa, H., F. Hasada, Y. Arai, K. Shimizu, M. Ohiva, and M. Ohki. 1993. A NotI restriction map of the entire long arm of human chromosome 21. Nature Genet. 4: $361-366$.

Krizman, D.B. and S.M. Berget. 1993. Efficient selection of 3'-terminal exons from vertebrate DNA. Nucleic Acids Res. 21: 5198-5202.

Leung, T., B.E. How, E. Manser, and L. Lim. 1994. Cerebellar beta 2-chimaerin, a GTPase-activating protein for p21 ras-related rac is specifically expressed in granule cells and has a unique N-terminal SH2 domain. J. Biol. Chem. 269: 12888-12892.

Lichter, P., T. Cremer, J. Borden, L. Manuelidis, and D.C. Ward. 1988. Delineation of individual human chromosomes in metaphase and interphase cells by in situ suppression hybridization using recombinant DNA libraries. Hum. Genet. 80: 224-234.

Lovett, M., J. Kere, and L.M. Hinton. 1991. Direct selection: A method for the isolation of cDNAs encoded by large genomic regions. Proc. Natl. Acad. Sci. 88: $9628-9632$.

Lucente, D., H.M. Chen, D. Shea, S.N. Samec, R. Chrast, C. Rossier, A. Buckler, S.E. Antonarakis, and M.K. McCormick. 1995. Localization of 102 exons to a $2.5 \mathrm{Mb}$ region of chromosome 21 involved in Down syndrome. Hum. Mol. Genet. 4: 1305-1311.

McInnis, M.G., A. Chakravarti, J. Blaschak, M.B. Petersen, V. Sharma, D. Avramopoulos, J.L. Blouin, U. Koenig, C. Brahe, T. Cox Matise, A.C. Warren, C.C. Talbot, Jr., C. Van Broeckhoven, M. Litt, and S.E. Antonarakis. 1993. A linkage map of human chromosome 21: 43 markers at average interval of 2.5 cM. Genomics 16: 562-571.

Murai, T., A. Kakizuka, T. Takumi, H. Ohkubo, and S. Nakanishi. 1989. Molecular cloning and sequence analysis of human genomic DNA encoding a novel membrane protein which exhibits a slowly activating potassium channel activity. Biochem. Biophys. Res. Commun. 161: 176-181.

Nathans, J., D. Thomas, and D.S. Hogness. 1986. Molecular genetics of human color vision: The genes encoding blue, green, and red pigments. Science 232: 193-202.

Nizetic, D., L. Gellen, R.M.J. Hamvas, R. Mott, A. Grigoriev, R. Vatcheva, G. Zehetner, M.L. Yaspo, A. Dutriaux, C. Lopes, J.M. Delabar, C. Van Broeckhoven, M.C. Potier, and H. Lehrach. 1994. An integrated YAC-overlap and "cosmid-pocket" map of the human chromosome 21. Hum. Mol. Genet. 3: 759-770.

Parimoo, S., S.R. Patanjali, H. Shukla, D.D. Chaplin, and S.M. Weissman. 1991. cDNA selection: Efficient PCR approach for the selection of cDNAs encoded in large chromosomal DNA fragments. Proc. Natl. Acad. Sci. 88: $9623-9627$.

Patterson, D., Z. Rahmani, D. Donaldson, K. Gardiner, and C. Jones. 1993. Physical mapping of chromosome 21. Progr. Clin. Biol. Res. 384: 33-50.

Peterson, A., N. Patil, C. Robbins, L. Wang, D.R. Cox, and R.M. Myers. 1994. A transcript map of the Down syndrome critical region on chromosome 21. Hum. Mol. Genet. 3: 1735-1742.

Saccone, S., A. De Sario, J. Wiegant, A.K. Raap, G. Della Valle, and G. Bernardi. 1993. Correlations between isochores and chromosomal bands in the human genome. Proc. Natl. Acad. Sci. 90: 11929-11933.

Soares, M.B., M.D. Bonaldo, P. Jelene, L. Su, L. Lawton, and A. Efstratiadis. 1994. Construction and characterization of a normalized cDNA library. Proc. Natl. Acad. Sci. 91: 9228-9232.

Soeda, E., D.X. Hou, K. Osoegawa, Y. Atshuchi, T. Yamagata, T. Shimokawa, H. Kishida, E. Soeda, S. Okano, I. Chumakov, D. Cohen, M. Raff, K. Gardiner, S.L. Graw, D. Patterson, P.D. Jong, L.K. Ashworth, T. Slezak, and A.V. Carrano. 1995. Cosmid assembly and anchoring to human chromosome 21. Genomics 25: 73-84.

Tassone, F., S. Cheng, and K. Gardiner. 1992. Analysis of chromosome 21 yeast artificial chromosome (YAC) clones. Am. J. Hum. Genet. 51: 1251-1264.

Tassone, F., H. Xu, H. Burkin, S. Weissman, and K. Gardiner. 1995. cDNA selection from $10 \mathrm{Mb}$ of chromosome 21 DNA: Efficiency in transcriptional mapping and reflections of the genome organization. Hum. Mol. Genet. 4: 1509-1518.

Watanbe, H., J.I. Sawada, K.I. Yano, K. Yamagucchi, M. Goto, and H. Handa. 1993. cDNA cloning of transcription factor E4TF1 subunits with ETS and Notch motifs. Mol. Cell. Biol. 13: 1385-1391.

$\mathrm{Xu}, \mathrm{H} ., \mathrm{H}$. Wei, F. Tassone, S. Graw, K. Gardiner, and S.M. Weissman. 1995. A search for genes from the dark band regions of human chromosome 21 . Genomics 27: 1-8.

Yaspo, M.-L., L. Gellen, R. Mott, B. Korn, D. Nizetic, A. Poustka, and H. Lehrach. 1995. Model for a transcript map of human chromosome 21: Isolation of new coding sequences from exon and enriched cDNA libraries. Hum. Mol. Genet. 4: 1291-1304.

Received May 20, 1996; accepted June 21, 1996. 


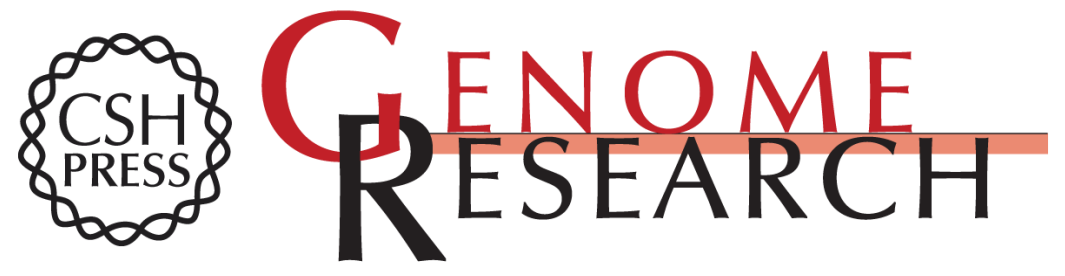

\section{Cloning of 559 potential exons of genes of human chromosome 21 by exon trapping.}

H Chen, R Chrast, C Rossier, et al.

Genome Res. 1996 6: 747-760

Access the most recent version at doi:10.1101/gr.6.8.747

References This article cites 38 articles, 9 of which can be accessed free at:

http://genome.cshlp.org/content/6/8/747.full.html\#ref-list-1

\section{License}

Email Alerting Receive free email alerts when new articles cite this article - sign up in the box at the Service top right corner of the article or click here.

\section{Affordable, Accurate Sequencing.}

To subscribe to Genome Research go to: https://genome.cshlp.org/subscriptions 